\title{
Synthesis, characterization and antibacterial activity of silver nanoparticles using Rhazya stricta
}

\author{
Adeeb Shehzad ${ }^{1}$, Munibah Qureshi ${ }^{1}$, Saima Jabeen ${ }^{1}$, Rizwan Ahmad ${ }^{2}$, Amira H. Alabdalall ${ }^{3}$, Meneerah \\ Abdulrahman Aljafary ${ }^{3}$, Ebtesam Al-Suhaimi ${ }^{\text {Corresp. } 3,4}$ \\ 1 Department of Biomedical Engineering and Sciences, School of Mechanical and Manufacturing Engineering, National University of Science and \\ Technology, Islamabad, Pakistan \\ 2 College of Clinical Pharmacy, Imam Abdulrahman Bin Faisal University, Dammam, Saudi Arabia \\ 3 Department of Biology, College of Sciences, Imam Abdulrahman Bin Faisal University, Dammam, Saudi Arabia \\ 4 Institute for Research and Medical Consultations, Imam Abdulrahman Bin Faisal University, Dammam, Saudi Arabia \\ Corresponding Author: Ebtesam Al-Suhaimi \\ Email address: ealsuhaimi@iau.edu.sa
}

Background Green synthesis of metallic nanoparticles has gained significant attention in the field of nano-medicine due to environment-friendly and cost-effective alternative in comparison to other physical and chemical methods. Several metals such as silver, gold, iron, titanium, zinc, magnesium, and copper have been subjected to nano-formulation for a wide range of useful applications. Silver nanoparticles (AgNPs) are playing a major role in the field of nano-medicine and nanotechnology. They are widely used in diagnostics, therapeutic and pharmaceutical industries. Studies have shown potential inhibitory antimicrobial, anti-inflammatory and anti-angiogenesis activities of AgNPs. Methods AgNPs have been synthesized using silver nitrate (AgNO3) and methanolic root extract of Rhazya stricta that belongs to the Apocynaceae family. Stability and dispersion of nanoparticles were improved by adding xylitol. Synthesized nanoparticles were characterized by UV-vis spectroscopy, scanning electron microscopy (SEM), Energy dispersive spectroscopy (EDS), X-ray diffractometer (XRD), and Fourier transforms infrared spectroscopy (FTIR). Furthermore, the antibacterial effect of the plant extract and the nanoparticles were evaluated against gram-positive (Bacillus subtilis) and gram-negative (Escherichia coli) bacteria. Results The Average size of AgNPs synthesized, was $20 \mathrm{~nm}$ with the spherical shape. Rhazya stricta based nanoparticles exhibited improved antibacterial activity against both gram-positive and negative strains. 
1 Synthesis, characterization and antibacterial activity of silver nanoparticles using $R$ hazya

2

\section{stricta}

$$
\text { Adeeb Shehzad }{ }^{1} \text {, Munibah Qureshi' }{ }^{1} \text {, Saima Jabeen }{ }^{1,} \text { Rizwan Ahmad², Amira H. Alabdalall², }
$$
Meneerah Abdulrahman Aljafary ${ }^{3}$, Ebtesam Al-Suhaimi ${ }^{3,}$ 4* $^{*}$

The first two authors equally contributed to this work

${ }^{1}$ Department of Biomedical Engineering and Sciences, School of Mechanical and Manufacturing Engineering, National University of Science and Technology, Islamabad, Pakistan

${ }^{2}$ College of Clinical Pharmacy, Imam Abdulrahman Bin Faisal University, Dammam, Saudi Arabia

${ }^{3}$ Department of Biology, College of Sciences, Imam Abdulrahman Bin Faisal University, Dammam, Saudi Arabia

${ }^{4}$ Institute for Research and Medical Consultations, Imam Abdulrahman Bin Faisal University, Saudi Arabia

\section{Correspondence*}

Ebtesam A Al-Suhaimi, Department of Biology, College of Sciences \& Institute for Research and Medical Consultations, Imam Abdulrahman Bin Faisal University, Saudi Arabia Email: ealsuhaimi@iau.edu.sa

Tel: +966133332444 


\section{Abstract}

24

25

26

27

28

29

\section{Background}

Green synthesis of metallic nanoparticles has gained significant attention in the field of nanomedicine due to environment-friendly and cost-effective alternative in comparison to other physical and chemical methods. Several metals such as silver, gold, iron, titanium, zinc, magnesium, and copper have been subjected to nano-formulation for a wide range of useful applications. Silver nanoparticles (AgNPs) are playing a major role in the field of nano-medicine and nanotechnology. They are widely used in diagnostics, therapeutic and pharmaceutical industries. Studies have shown potential inhibitory antimicrobial, anti-inflammatory and antiangiogenesis activities of AgNPs.

\section{Methods}

AgNPs have been synthesized using silver nitrate (AgNO3) and methanolic root extract of Rhazya stricta that belongs to the Apocynaceae family. Stability and dispersion of nanoparticles were improved by adding xylitol. Synthesized nanoparticles were characterized by UV-vis spectroscopy, scanning electron microscopy (SEM), Energy dispersive spectroscopy (EDS), Xray diffractometer (XRD), and Fourier transforms infrared spectroscopy (FTIR). Furthermore, the antibacterial effect of the plant extract and the nanoparticles were evaluated against gram-positive (Bacillus subtilis) and gram-negative (Escherichia coli) bacteria.

\section{Results}

2 The Average size of AgNPs synthesized, was $20 \mathrm{~nm}$ with the spherical shape. Rhazya stricta based nanoparticles exhibited improved antibacterial activity against both gram-positive and negative strains. 


\section{Introduction}

6 Nanotechnology is a new, fascinating and fast growing revolution in the interdisciplinary fields including biomedical, therapeutics, diagnostics and materials science. Nanotechnology involves creation and manipulation of materials at the nano scale by altering their molecular structure (Rajasekharreddy \& Rani, 2014). Different metals such as silver, gold, iron, titanium, zinc, magnesium and copper have been subjected to nano-formulation for a wide range of beneficial applications by adopting various physical, chemical and biological techniques (Ponarulselvam et al., 2012). Green synthesis is an alternative approach for synthesizing nanoparticles (NPs) using natural resources such as microorganisms and medicinal plants as reducing agents. NPs synthesized by the green method are highly stable, environmental friendly, biocompatible, cost effective, less toxic and safe for diagnostic and therapeutic purpose (Ponarulselvam et al., 2012; Rajasekharreddy \& Rani, 2014; Verma \& Mehata, 2016).

Silver based nano-materials play a major role in the field of nano-medicine and nanotechnology (Logeswari \& Abraham, 2015). Several studies have also proved antimicrobial activity of AgNPs against several pathogenic and multidrug-resistant microorganisms (Singh et al., 2016). Various chemical and physical techniques have been reported for the synthesis of AgNPs, however many of those techniques require costly chemicals which are also toxic (Ahmad et al., 2017). Therefore, the synthesis of NPs by using plant isolated compound could be an attractive strategy in the field of nanotechnology as it offers several advantages such as cost-effective, eco-friendly, rapid synthesis and high yield.

Owing to huge medicinal properties of plants, herein, it is reported green technique for the synthesis of silver nanoparticles by using roots of Rhazya stricta. It is a small, glabrous, erect shrub that contains alkaloids, flavonoids and phenolic compounds (Bukhari et al., 2017). Rhazya stricta 
68 is also known as Harmal, widely distributed in Saudi Arabia and South Asia (Bukhari et al., 2017;

69 Obaid et al., 2017). Seed oil from Harmal is considered a potential rich source of d-tocopherol, a

70

71

72

73

74

major form of vitamin $\mathrm{E}$ (Nehdi et al., 2016). It is used for treating numerous diseases such as obesity, diabetes mellitus, sore throat, cardiovascular, metabolic, neurodegenerative diseases as well as cancers (Alagrafi et al., 2017). It exhibits anti-oxidant, anti-carcinogenic, antimicrobial, anti-dramatist, antihypertensive (VanBeek et al., 1985), antidepressant, anti-inflammatory, antipyretic, antifungal and herbicidal activities (Alagrafi et al., 2017; Ali et al., 2000; Baeshen et al., 2010; Lantero, 2014; Sarfaraz, 2012; Van Beek et al., 1985). Previously, gold nanoparticles (AuNPs) synthesized with extract of Rhazya stricta displayed better anticancer activity against MFC-7 cell lines (Baeshen, 2013). In this study, we have synthesized AgNPs by using root extract of Rhazya stricta plant as a reducing agent along with xylitol (sugar). The synthesized AgNPs was tested for antibacterial activity against gram-positive (Bacillus subtilis) and gram-negative bacteria (Escherichia coli).

\section{Materials and Methods}

\subsection{Chemicals and reagents}

AgNO3 and xylitol were purchased with $\geq 99.0 \%$ purity from Sigma-Aldrich. De-ionized water was used for reaction and Whatman filter papers $(125 \mathrm{~mm})$ were used for the purification and filtration.

\subsection{Preparation of root extract}

Rhazya stricta was collected from southern part of Pakistan and identified in Taxonomy lab, Department of Botany at Arid Agriculture University Rawalpindi Pakistan. The voucher specimen number MAQ.2014.B313, was deposited in Department Herbarium of Botany, Arid Agriculture 
91 University Rawalpindi. The roots of the plant were washed thrice with de-ionized water and shade

92

93

94

95

96

97 dried. Extracts were prepared by soaking $147 \mathrm{~g}$ of dried roots in $80 \%$ methanol at room temperature for three days, and then filtered using Whatman filter paper $(125 \mathrm{~mm})$. The solvent was evaporated using a rotary evaporator. The resulted extract after drying was $13 \mathrm{~g}$.

\subsection{Biosynthesis of silver nanoparticles}

For the synthesis of AgNPs, $10 \mathrm{~g}$ of dried extract was dissolved in $18 \mathrm{~mL}$ methanol and placed at $4^{\circ} \mathrm{C} .1 \mathrm{mM}$ solution of $\mathrm{AgNO}_{3}$ was prepared in deionized water. $6 \mathrm{~mL}$ methanol-extracted plant roots were added drop by drop in $100 \mathrm{ml} \mathrm{AgNO}_{3}(1 \mathrm{mM})$ with continuous shaking. Another reaction was carried out using the same amount of extract and $100 \mathrm{~mL}$ of $\mathrm{AgNO}_{3}$ with $6 \mathrm{~mL}$ xylitol $\left(10^{-2}\right.$ M). Then both reactions were heated separately using a magnetic stirrer at $60{ }^{\circ} \mathrm{C}$ for two hours. The change in color was the indication for synthesis of NPs [Fig. 1].

For characterization of AgNPs, the sample was centrifuged for 20 minutes at 12000rpm. The supernatant was discarded to get rid of any uncoordinated material. The Sample was then washed thrice with distilled water to eliminate extra proteins or enzymes. After sonication, the sample was dried with a vacuum drier for an overnight at $50^{\circ} \mathrm{C}$.

\subsection{UV-Visible Absorbance spectroscopy}

Bio-reduction of $\mathrm{Ag}^{+}$ions in $\mathrm{AgNO} 3$ solution was observed by ultraviolet-visible (UV-Vis) spectroscopy (UV-2800, BMS). UV spectrums for $250 \mu 1,350 \mu \mathrm{L}, 450 \mu \mathrm{L}, 550 \mu \mathrm{L}, 650 \mu \mathrm{L}$ concentrations of plant extract in $10 \mathrm{~mL}$ of $\mathrm{AgNO} 3$ solution were monitored. The UV-Vis absorption spectra for AgNPs was observed in a range of 300-600nm with UV-2800 spectrophotometer. 


\section{2.5. Fourier Transform Infrared Spectroscopy (FTIR)}

115 Biomolecules responsible for reducing $\mathrm{Ag}^{+}$were analyzed by Fourier transform infrared (FTIR)

116 spectrometer. FTIR spectroscopy is an experimental technique used for analysis of functional

117 groups, molecular structure and chemical bonding of organic and inorganic samples, by producing

118 an infrared absorption spectrum (Perklin Elmer Spectrum 100) (Verma \& Mehata, 2016).

119

120

\subsection{X-ray Diffraction (XRD)}

121 The structural characterization and crystalline nature of AgNPs were determined by X-ray 122 diffractometer (D8 Advance, Bruker) for the vacuumed dried AgNPs (Ashraf et al., 2016).

\subsection{Scanning Electron Microscopy (SEM)}

125 The size and morphology of AgNPs were investigated using JEOL-6490A-JSMScanning Electron Microscope. Elemental composition of AgNPs was determined by Energy Dispersive

127 Spectroscopy (EDS).

\subsection{Antibacterial Activity}

130

The antibacterial activity of the extract and AgNPs was evaluated against Escherichia coli, and Bacillus subtilis using disk diffusion method (Hu et al., 2017). Disks were soaked with distilled water (negative control), standard antibiotic cefipime (positive control) with the trade name of maxipime (glaxosmithkline), Rhazya stricta extract and the AgNPs solution with and without

134 xylitol addition separately. $50 \mu \mathrm{L}$ concentration of AgNPs was used to ensure identification of 135 antibacterial activity. Then the plates were incubated for $24-48$ hours at $37^{\circ} \mathrm{C}$ and zone of 136 inhibition was measured for both bacterial strains. 


\section{RESULTS}

\subsection{UV-VIS Spectroscopy}

140 Synthesis of nanoparticles started after the addition of root extract of Rhazya stricta into an 141 aqueous solution of AgNO3. The change in color from pale yellow to orange brown after 2 hours 142 heating $\left(60^{\circ} \mathrm{C}\right)$ on magnetic stirrer indicated the formation of reduced silver [Fig. $\mathbf{2 A}$ ].

143 To examine further AgNPs in aqueous suspensions, UV-Vis spectroscopy was used. As shown in 144 the Fig. 2B, the absorption peaks of AgNPs synthesized by Rhazya stricta root extract were 145 detected at 380, 392, 402, 414 and 427nm wavelength. The increasing concentration of plant extracts also increased the broadening of the peak indicating the increased size of NPs. Previous studies indicated that the spherical AgNPs have absorption bands at around $400 \mathrm{~nm}$ in the UV visible spectra (Nasir, Mohammed, \& Samir, 2016). These results indicate that the spherical AgNPs have absorption bands at around $402 \mathrm{~nm}$ in the UV visible spectra. Thus, it can be reported that particle size of AgNPs is highly subjective to the concentration of root extract.

\subsection{SEM}

For further confirmation, the size and shape of AgNPs, SEM was performed. Fig. 3A and B depict the formation of spherical shape NPs. It was noticed that AgNPs synthesized only with plant extract have shown more agglomeration [Fig.3A], while those synthesized with the addition of xylitol were not agglomerated, well dispersed and with average particle size of $20 \mathrm{~nm}$.

\section{3.3. Elemental analysis}

158 The AgNPs synthesized using Rhazya stricta were also characterized by EDX analysis, which

159 further confirmed the reduction of silver ion. The Optical absorption peak was recorded almost at 
$1603 \mathrm{keV}$, which is obvious for silver nano-crystals absorption because of surface Plasmon resonance

161 [Fig. 4]. The EDX spectrum has shown silver peak along with oxygen and chlorine peaks. The

162 chlorine and oxygen peaks were may be attributed to glass biomolecules that were present on the

163 surface of silver nanoparticles or to chlorine on the glass slides that were used for sample

164 preparation [Fig. 4].

165

166

\subsection{XRD}

167

168

169

170

171

172

173

174

175

176

177

178

179

180

181

182

The dry powders of AgNPs synthesized with root extract of Rhazya stricta were subjected to XRD analysis. XRD patterns of synthesized AgNPs are shown in Fig.5. The synthesized NPs were of crystalline nature. The XRD pattern has shown the intense five peaks of NPs at $31.99,45.5,54.85$, 57.52 and 67.24, were indexed to face-centered cubic structures of AgNPs. The XRD peaks revealed that AgNPs formed using Rhazya stricta root extract were crystalline and spherical in shape. The average nano size was confirmed by applying Debye-Scherrer formula $D=K \lambda / \beta \cos \theta$ which was found to be $20 \mathrm{~nm}$.

\subsection{FTIR}

FTIR spectroscopy was used to investigate. FTIR analysis was done to identify biomolecules that are responsible for $\mathrm{Ag}+$ ions reduction and capping of biologically reduced AgNPs synthesized by Rhazya stricta root extract along with xylitol. Fig.6A shows the FTIR spectrum of xylitol displayed bands at 3362.59 (OH of alcohol) and 1417.88 (C-H bending of alkane). Fig.6B shows the FTIR spectrum of root extract of Rhazya stricta plant that is showing peaks at 724, 1024, 1455 , $1687,2123,2921$ and $3374 \mathrm{~cm}^{-1}$. A peak at $3374 \mathrm{~cm}^{-1}$ indicated stretching of the $\mathrm{N}-\mathrm{H}$ bond of amino groups and presence of attached hydroxyl (-OH) group. The absorption peaks at $2921 \mathrm{~cm}^{-1}$ 
183 could be due to stretching of $-\mathrm{CH}$ functional groups. The peak at $1687 \mathrm{~cm}^{-1}$ corresponds to $\mathrm{C}-\mathrm{O}$

184 stretching in the carboxyl attached to the amide linkage in amide I. The absorption band at 1455

185 indicated the presence of C-N stretching in amide. The two bands present at 1024 and $742 \mathrm{~cm}^{-1}$ 186 could be indicative of the -O- stretching vibrations of aromatic and aliphatic amines (Gou et al., 187 2015). Fig.6C and Fig. 6D show FTIR spectra for AgNPs synthesized using only Rhazya stricta 188 plant and along with xylitol.

\subsection{Antimicrobial activity of AgNPs}

Plant mediated synthesis of AgNPs exhibited tremendous antibacterial activity against various bacterial strains. For this purpose, the antibacterial activity of AgNPs was examined with various concentrations of root extract against Bacillus subtilis for gram-positive and Escherichia coli for gram-negative strains. As shown in the Fig.7A, and C, three different concentrations $(450 \mu \mathrm{L}$, $550 \mu \mathrm{L}$ and $650 \mu \mathrm{L}$ ) of plant extract in $10 \mathrm{~mL}$ of $\mathrm{AgNO} 3$ were used to test the antibacterial activity. When concentration was increased from $450 \mu \mathrm{L}$ to $550 \mu \mathrm{L}$, the zone of inhibition also increased, however, at $650 \mu \mathrm{L}$, zone of inhibition was observed smaller than $550 \mu \mathrm{L}$ (Fig. 7A and C). The positive control $10 \mathrm{mM}$ of cefipime exhibited maximum zone of inhibition, whereas distilled water, the negative control shown no inhibition on both strains (Fig. 7B and D). The AgNPs synthesized by Rhazya stricta root extract along with xylitol displayed better antibacterial activity as compared to plant extract only, because xylitol increased the stability and decreased the agglomeration of synthesized AgNPs. Thus, uniform distribution of NPs enhanced the antibacterial activity of synthesized AgNPs with root extract of Rhyza stricta. 
205

206

207

208

209

210

211

212

213

214

215

216

217

218

219

220

221

222

223

224

225

226

227

\subsection{Time-dependent effect of AgNPs}

Once the concentration-dependent effect was confirmed, the effect of AgNPs synthesized using Rhazya stricta root extract was examined for its time dependent activity. The $550 \mu \mathrm{L}$ of AgNPs with Rhazya stricta root extract was tested further with and without xylitol against bacillus subtilis (gram-positive) and Escherichia coli (gram-negative). As shown in Fig.8A and B, AgNPs with Rhazya stricta root extract and xylitol have shown an increased zone of inhibition as compared to their individual zone of inhibition. These results confirm the enhanced antibacterial effect of AgNPs synthesized with Rhazya stricta root extract and xylitol.

\subsection{Differential effect of AgNPs against gram-negative and positive pathogens}

The synthesized silver nanoparticles had more inhibition effect on Escherichia coli as compared to Bacillus subtilis as shown in Fig. 9A and B. These results further confirmed that AgNPs synthesized with Rhazya stricta root extract have better bactericidal effects against gram-negative strains as compared to gram-positive strains.

\section{DISCUSSION}

Green synthesis of AgNPs could significantly overcome the problem of using chemical agents that cause various adverse effects. Therefore, green synthesis of NPs is environment-friendly approach (Gan \& Li, 2012; Wang et al., 2017). Rhazya stricta plant roots possess antibacterial activity that is considerably enhanced after incorporation with NPs. The characterization techniques advocated the stability of the synthesized AgNPs. Experimentally, Xylitol has not the ability to reduce silver ions, but it is possibly involved in the capping of the synthesized AgNPs by electrostatic attraction or binding with the protein groups present in the extract through hydrogen bonding and enhanced 
228 the silver nanoparticle's stability. It also protected the NPs from agglomeration (Kaviya et al.,

229 2011). Synthesis of the AgNPs starts with the change in color from pale yellow to orange brown

230 upon the addition of Rhazya stricta root extract [Fig. 2A]. It has been reported that excitation of

231 surface Plasmon resonance is responsible for yellowish brown color of AgNPs in aqueous solution

232 (Kaviya et al., 2011). This surface Plasmon vibration confirmed the biotransformation from an

233 ionic form to silver particles (Huang et al., 2007). Upon addition of Rhazya stricta root extract in

234 the aqueous solution of AgNO3 and xylitol, the color changed from pale yellow to orange brown

235 due to reduction of silver ion [Fig. 2A]. It was also noticed that increase in the concentration of

236 root extract in the synthesis reaction, increases the particle size. Further increase in plant extract

237 concentration shown noisy and broadened peak at UV-Vis spectrum. Current XRD results of

238 synthesized AgNPs with root extract of Rhazya stricta confirmed the structure of AgNPs as face-

239 centered cubic (fcc) with crystalline nature (Li et al., 2012). The EDX spectrum has shown clear

240 silver signal along with weak oxygen and chlorine peak, which might be due to the interaction and

241 binding of biomolecules to the surface of AgNPs (Kalainila et al., 2014).

242 FTIR analysis was performed to confirm that the bio-compounds involved in the reduction of ionic

243 and capping of the reduced AgNPs synthesized by Rhazya stricta root extract along with xylitol.

244 Fig. 6A shows FTIR spectrum of xylitol, it gave bands at 3362.59 (OH of alcohol) and 1417.88

245 (C-H bending of alkane). Fig. 6B represents the FTIR spectrum of root extract of Rhazya stricta

246 plant; it gave peaks at 724,1024, 1455,1687, 2123,2921 and $3374 \mathrm{~cm}^{-1}$. These peaks are expected

247 to be related with amide I shift due to carbonyl stretch in proteins $\left(1687 \mathrm{~cm}^{-1}\right),-\mathrm{C}-\mathrm{H}-$ stretch of

248 amine $\left(2921 \mathrm{~cm}^{-1}\right), \mathrm{C}-\mathrm{N}$ stretching vibration of amine $\left(1455 \mathrm{~cm}^{-1}\right)$, and -O- stretching vibrations

249 of aliphatic and aromatic amines $\left(1024\right.$ and $\left.742 \mathrm{~cm}^{-1}\right)$, respectively (Gou et al., 2015; Wang et al.,

250 2017). A peak at $3374 \mathrm{~cm}^{-1}$ indicated the stretching of the $\mathrm{N}-\mathrm{H}$ bond of amino groups and shown 
251 the presence of bonded hydroxyl (-OH) group (Gou et al., 2015; Hu et al., 2017; Wang et al.,

252 2017). After the formation of AgNPs peaks were shifted to little higher wavenumber as compared

253 to plant extract as indicated by Fig. 6C. Xylitol did not reduce the silver ions in the solution, but

254 it was used to cap/coat the synthesized AgNPs through electrostatic attraction or hydrogen bonding

255 with protein groups that further aided in more stability and better dispersion of NPs Fig. 6D. FTIR

256 spectrum of the Rhazya stricta roots extract confirmed the presence of carboxyl $(-\mathrm{C}=\mathrm{O})$, hydroxyl

$257(-\mathrm{OH})$ and amine $(\mathrm{N}-\mathrm{H})$ groups of Rhazya stricta roots extract and further revealed their

258 involvement in the reduction of silver ion to metallic silver nanoparticles (Nasir, Mohammed, \&

259 Samir, 2016). Plant extract contains proteins that cap the silver nanoparticles through carboxyl or

260 amino group present in protein (Kaviya et al., 2011). It is believed that proteins of the root extract

261 of Rhazya stricta could bind to AgNPs through either free amino or carboxyl groups (Nasir et al.,

262 2016). The presence of the residual plant extract in the sample is due to the similarity of the spectra

263 with little marginal shifts in peak position (Saiqa, 2015). Thus these results have shown that the

264 functional groups of bio-compounds present in the root extract of Rhazya stricta have key role in

265 the reduction as well as capping of AgNPs.

266 Previous studies have also reported the antibacterial activity of AgNPs against gram negative and

267 gram positive strains of bacteria (Singh et al., 2008). It is well recognized that the antibacterial

268 effect of AgNPs is size and dose dependent. The results were supported by previously reported

269 studies (Sana \& Dogiparthi, 2018), which have shown that AgNPs have more potential against

270 gram-negative bacteria then gram positive bacteria (Fig. 7A and C). Increase in the size of NPs

271 reduced their antibacterial activity (Kaviya et al., 2011). Rhazya stricta-AgNPs exhibited strong

272 antioxidant and antibacterial effects It is also concluded that the antibacterial activity of AgNPs 
273 depends on the concentration of root extract and quantity of AgNPs in the medium (Rauf et al.,

274 2016).

275

276 Conclusion

277 AgNPs synthesized using Rhazya stricta root extract along with xylitol have shown potential

278 antimicrobial activity because they were mono dispersed, stable and have less aggregation. Plant

279 acted as a reducing agent in the synthesis of AgNPs and xylitol enhanced the dispersion of 280 nanoparticles. Smaller size of NPs displayed better antibacterial activity. Antibacterial activity of 281 Rhazya stricta plant root was enhanced when it was incorporated with AgNPs synthesis. Thus, 282 synthesized AgNPs increases the therapeutic efficacy, strengthen the medicinal values of Rhazya 283 stricta and provides a potent source of an antimicrobial agent against gram positive and gram 284 negative organisms. Future studies are needed to uncover the underlying mechanism of 285 bacteriostatic or bactericidal effects of green synthesized AgNPs.

286

287

288

289

290

291

292

293

294

295

296

297

298

299

300

301

302

303

304

305 


\section{References}

308

309

310

311

312

313

314

315

316

317

318

319

320

321

322

323

324

325

326

327

Ahmad, A., Wei, Y., Ullah, S., Shah, S. I., Nasir, F., Shah, A., ... Yuan, Q. (2017). Synthesis of phytochemicals-stabilized gold nanoparticles and their biological activities against bacteria and Leishmania. Microb Pathog, 110, 304-312.

https://doi.org/10.1016/j.micpath.2017.07.009

Alagrafi, F. S., Alawad, A. O., Abutaha, N. M., Nasr, F. A., Alhazzaa, O. A., Alharbi, S. N., ... Wadaan, M. A. (2017). In vitro induction of human embryonal carcinoma differentiation by a crude extract of Rhazya stricta. BMC Complement Altern Med, 17(1), 1-13. https://doi.org/10.1186/s12906-017-1852-7

Ali, B. H., Al-Qarawi, A. A., Bashir, A. K., \& Tanira, M. O. (2000). Phytochemistry, pharmacology and toxicity of Rhazya stricta Decne: A review. Phytother. Res, 14(4), 229 234. https://doi.org/10.1002/1099-1573(200006)14:4 HYPERLINK

Ashraf, J. M., Ansari, M. A., Khan, H. M., Alzohairy, M. A., \& Choi, I. (2016). Green synthesis of silver nanoparticles and characterization of their inhibitory effects on AGEs formation using biophysical techniques. Scientific Reports, 6(February), 1-10. https://doi.org/10.1038/srep20414

Baeshen, N. A., Lari, S. A., Doghaither, H. A. R. Al, \& Ramadan, H. A. I. (2010). Effect of Rhazya stricta extract on rat adiponectin gene and insulin resistance, 6(12), 1237-1245.

Baeshen MN. 2013. The effect of biosynthesized Rhazya stricta leaf extracts with gold nanoparticles on breast cancer cell lines. Biological systems 5:1110-1118. DOI: 10.1039/c3ib40053k. 
328 Bukhari, N. A., Al-Otaibi, R. A., \& Ibhrahim, M. M. (2017). Phytochemical and taxonomic

329 evaluation of Rhazya stricta in Saudi Arabia. Saudi J Biol Sci, 24(7), 1513-1521.

$330 \quad$ https://doi.org/10.1016/j.sjbs.2015.10.017

331 Gan, P. P., \& Li, S. F. Y. (2012). Potential of plant as a biological factory to synthesize gold and

332 silver nanoparticles and their applications. Rev. Environ. Sci. Biotechnol, 11(2), 169-206.

$333 \quad$ https://doi.org/10.1007/s11157-012-9278-7

334 Gou, Y., Zhou, R., Ye, X., Gao, S., \& Li, X. (2015). Highly efficient in vitro biosynthesis of

335 silver nanoparticles using Lysinibacillus sphaericus MR-1 and their characterization. Sci

336 Technol Adv Mater, 16(1). https://doi.org/10.1088/1468-6996/16/1/015004

337 Hu, G., Liang, G., Zhang, W., Jin, W., Zhang, Y., Chen, Q., ... Zhang, W. (2017). Silver

338 nanoparticles with low cytotoxicity: controlled synthesis and surface modification with

339 histidine. J. Mater. Sci, 53(7), 1-13. https://doi.org/10.1007/s10853-017-1940-6

340 Huang, J., Li, Q., Sun, D., Lu, Y., Su, Y., Yang, X., ... Chen, C. (2007). Biosynthesis of silver

341 and gold nanoparticles by novel sundried Cinnamomum camphora leaf. Nanotechnology,

342 18(10). https://doi.org/10.1088/0957-4484/18/10/105104

343 Kalainila, P., Subha, V., Ravindran, R. S. E., \& Renganathan, S. (2014). SYNTHESIS AND

344 CHARACTERIZATION OF SILVER NANOPARTICLE FROM Erythrina indica. Asian J

$345 \quad$ Pharm Clin Res, 7(2), 39-43.

346 Kaviya, S., Santhanalakshmi, J., \& Viswanathan, B. (2011). Green synthesis of silver

347 nanoparticles using Polyalthia longifolia leaf extract along with D-sorbitol: Study of

348 antibacterial activity. J Nanotech, 2011. https://doi.org/10.1155/2011/152970

349 Lantero, A. (2014). Sewarine, an indole alkaloid from Rhazya stricta and a $\kappa$ opioid receptor

350 antagonist, induces apoptosis via caspase activation in various cancer cell lines, and inhibits 


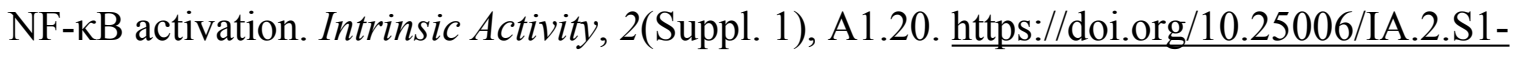

352

353

354

355

356

357

358

359

360

361

362

363

364

365

366

367

368

369

370

371

372

373

$\underline{\mathrm{A} 1.20}$

Li, G., He, D., Qian, Y., Guan, B., Gao, S., Cui, Y., ... Wang, L. (2012). Fungus-mediated green synthesis of silver nanoparticles using aspergillus terreus. Int. J. Mol. Sci, 13(1), 466-476. $\underline{\text { https://doi.org/10.3390/ijms13010466 }}$

Logeswari, P., Silambarasan, S., \& Abraham, J. (2015). Synthesis of silver nanoparticles using plants extract and analysis of their antimicrobial property. J. Saudi Chem. Soc., 19(3), 311317. https://doi.org/10.1016/j.jscs.2012.04.007

Nasir, G. A., Mohammed, A. K., \& Samir, H. F. (2016). Biosynthesis and Characterization of Silver Nanoparticles Using Olive Leaves Extract and Sorbitol. Iraqi J Biotech, 15(1), 2232.

Nehdi, I. A., Sbihi, H. M., Tan, C. P., \& Al-Resayes, S. I. (2016). Seed oil from Harmal (Rhazya stricta Decne) grown in Riyadh (Saudi Arabia): A potential source of $\delta$-tocopherol. $J$ Saudi Chem Soc, 20(1), 107-113. https://doi.org/10.1016/j.jscs.2014.09.005

Obaid, A. Y., Voleti, S., Bora, R. S., Hajrah, N. H., Omer, A. M. S., Sabir, J. S. M., \& Saini, K. S. (2017). Cheminformatics studies to analyze the therapeutic potential of phytochemicals from Rhazya stricta. Chem Cent J, 11(1), 1-21. https://doi.org/10.1186/s13065-017-0240-1

Painuli, R., Joshi, P., \& Kumar, D. (2018). Cost-effective synthesis of bifunctional silver nanoparticles for simultaneous colorimetric detection of $\mathrm{Al}(\mathrm{III})$ and disinfection. Sensors and Actuators, B: Chemical, 272(February), 79-90.

https://doi.org/10.1016/j.snb.2018.05.131

Ponarulselvam, S., Panneerselvam, C., Murugan, K., Aarthi, N., Kalimuthu, K., \& Thangamani, S. (2012). Synthesis of silver nanoparticles using leaves of Catharanthus roseus Linn. G. 
374

375

376

377

378

379

380

381

382

383

Don and their antiplasmodial activities. Asian Pac J Trop Biomed, 2(7), 574-580. https://doi.org/10.1016/S2221-1691(12)60100-2

Rajasekharreddy, P., \& Rani, P. U. (2014). Biofabrication of Ag nanoparticles using Sterculia foetida L. seed extract and their toxic potential against mosquito vectors and HeLa cancer cells. Mater. Sci. Eng. C, 39(1), 203-212. https://doi.org/10.1016/j.msec.2014.03.003

Rauf, Abdul, Ajmal Khan, Zara Dawood, Ghias Uddin, Umar Farooq AM. 2016. Synthesis, Characterization and Bioactivities of Silver Nanoparticles using Ethanolic and Aqueous Extracts of Rhazya strictica. In: NanosmatAt: The University of Texas at Arlington, Texas, USA. 1-704.

Saiqa Ikram, S. A. (2015). Silver Nanoparticles: One Pot Green Synthesis Using Terminalia ` Arjuna Extract for Biological Application. $J$ Nanomed Nanotech, 6(4). https://doi.org/10.4172/2157-7439.1000309

Sana, S. S., \& Dogiparthi, L. K. (2018). Green synthesis of silver nanoparticles using Givotia moluccana leaf extract and evaluation of their antimicrobial activity. Materials Letters, 226, 47-51. https://doi.org/10.1016/j.matlet.2018.05.009

Sarfaraz Khan Marwat. (2012). A review of phytochemistry, bioactivities and ethno medicinal uses of Rhazya stricta Decsne (Apocynaceae). Afr J Microbiol Res, 6(8), 1629-1641. https://doi.org/10.5897/AJMRx11.024

Singh, M., Singh, S., Prasad, S., \& Gambhir, I. S. (2008). Nanotechnology in Medicine and Antibacterial Effect of. Dig J Nanomater Biostruct, 3(3), 115-122. Retrieved from $\underline{\text { http://tse.colloidalsilverkillsviruses.com/pdf/n HYPERLINK }}$

Singh, P., Kim, Y. J., Wang, C., Mathiyalagan, R., \& Yang, D. C. (2016). The development of a green approach for the biosynthesis of silver and gold nanoparticles by using Panax ginseng 
397

398

399

400

401

402

403

404

405

406

407

408

409

410

411

412

413

414

415

416

417 Figure 4: Energy Dispersive X-Ray image of AgNPs synthesized using Rhazya stricta.

418 Figure 5: X-Ray Diffraction (XRD) image of the AgNPs synthesized using Rhazya stricta.

root extract, and their biological applications. Artif Cells Nanomed Biotechnol, 44(4), 11501157. https://doi.org/10.3109/21691401.2015.1011809

Van Beek, T. A., Verpoorte, R., Svendsen, A. B., \& Fokkens, R. (1985). Antimicrobially active alkaloids from tabernaemontana chippii. J. Nat. Prod, 48(3), 400-423. https://doi.org/10.1021/np50039a008

Verma, A., \& Mehata, M. S. (2016). Controllable synthesis of silver nanoparticles using Neem leaves and their antimicrobial activity. J Radiat Res Appl Sc, 9(1), 109-115. https://doi.org/10.1016/j.jrras.2015.11.001

Wang, D., Markus, J., Wang, C., Kim, Y.-J., Mathiyalagan, R., Aceituno, V. C., ... Yang, D. C. (2017). Green synthesis of gold and silver nanoparticles using aqueous extract of Cibotium barometz root. Artif Cells Nanomed Biotechnol, 45(8), 1548-1555. https://doi.org/10.1080/21691401.2016.1260580

\section{Figure Legends}

Figure 1: Schematic presentation of methodology for synthesis of AgNPs with root extract of Rhazya stricta.

Figure 2: (A) Change in color after synthesis of AgNPs. (B) Concentration dependent UV-Vis Spectra of AgNPs of Rhazya stricta.

Figure 3: SEM showing spherical AgNPs. (A) AgNPs of plant extract only (B) AgNPs of plant extract with xylitol 
419 Figure 6: (A) FTIR of Xylitol. (B) FTIR of medicinal plant Rhazya stricta. (C) FTIR of AgNPs 420 using Rhazya stricta. (D) FTIR of AgNPs using Rhazya stricta along with xylitol.

421 Figure 7: (A) Concentration dependent effect of Bacillus subtilis. (B) Graphical presentation for 422 concentration dependent effect of Bacillus subtilis. (C) Concentration dependent effect of 423 Escherichia coli. (D) Graphical presentation for concentration dependent effect of Escherichia 424 coli.

425 Figure 8: (A) Time dependent effect of Bacillus subtilis. (B) Graphical presentation for time 426 dependent effect of Bacillus subtilis. (C) Time dependent effect of Escherichia coli. (D) Graphical 427 presentation for time dependent effect of Escherichia coli.

428 Figure 9: (A) Difference between effect of silver nanoparticles of R. stricta along with xylitol on 429 Escherichia coli and Bacillus subtilis. (B) Graphical presentation for comparative effect of AgNPs 430 against Escherichia coli and Bacillus subtilis. 
Figure 1

Methodology for synthesis of AgNPs

Schematic presentation of methodology for synthesis of AgNPs with root extract of Rhazya stricta.

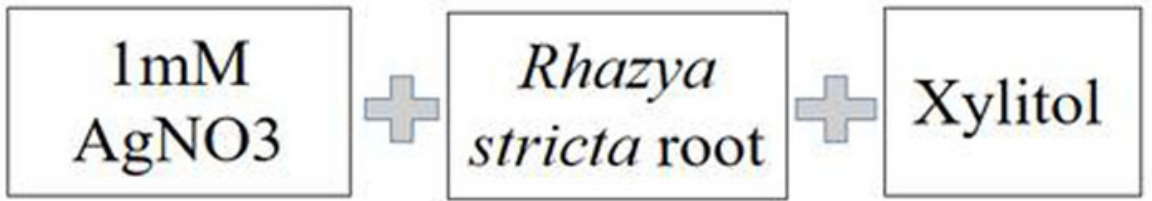

Mixing

Magnetic stirrer

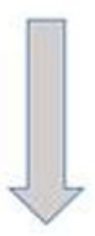

Orange brown reaction mixture
Nanoparticles

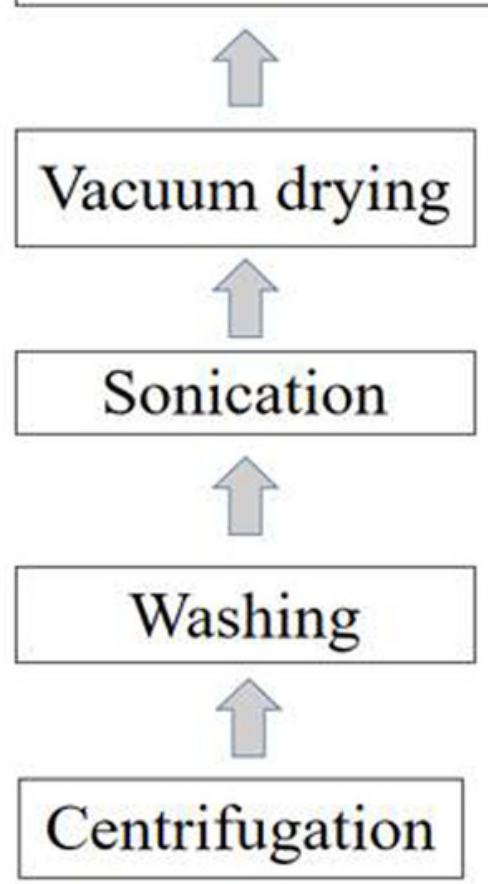




\section{Figure 2}

Charecterization of AgNPs

(A) Change in color after synthesis of AgNPs. (B) Concentration dependent UV-Vis Spectra of AgNPs of Rhazya stricta.

Photo credit: Saima Jabeen

$\mathbf{A}$

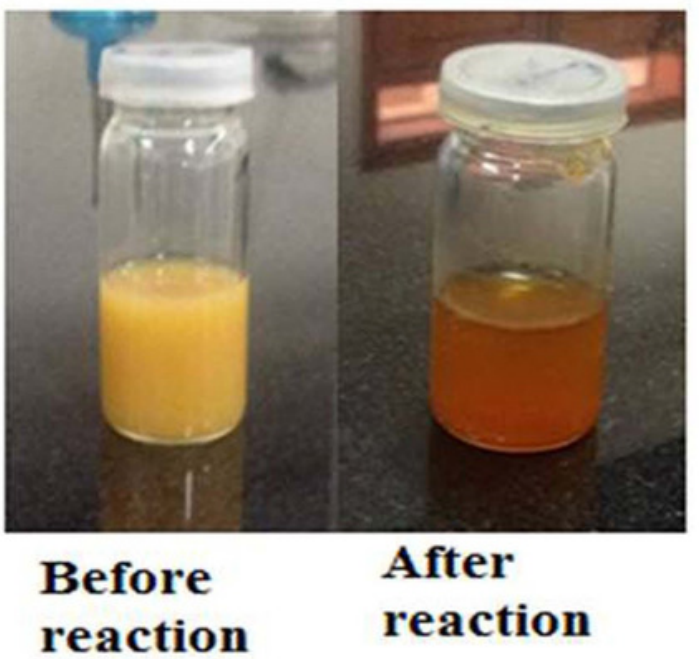

B

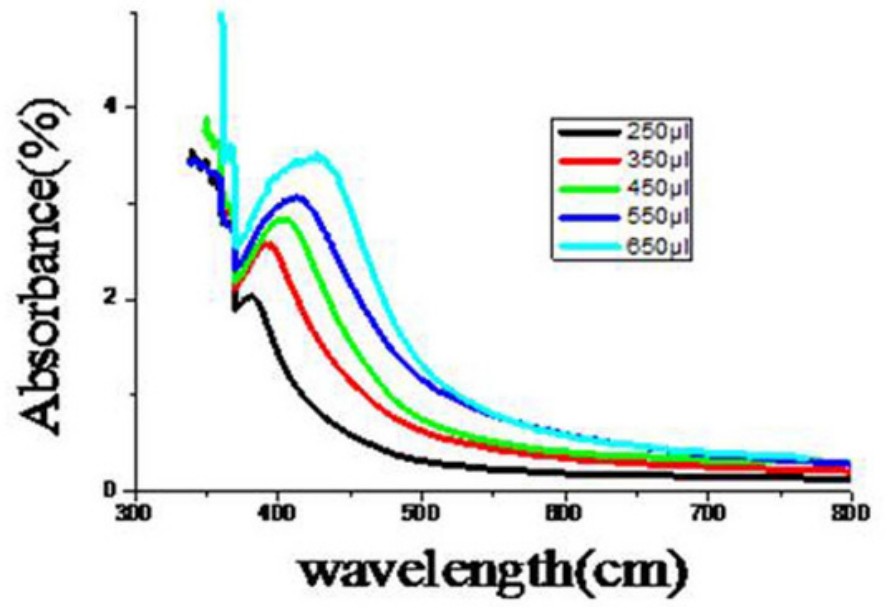


Figure 3

SEM images of AgNPs

(A) AgNPs of plant extract only (B) AgNPs of plant extract with xylitol

(A)

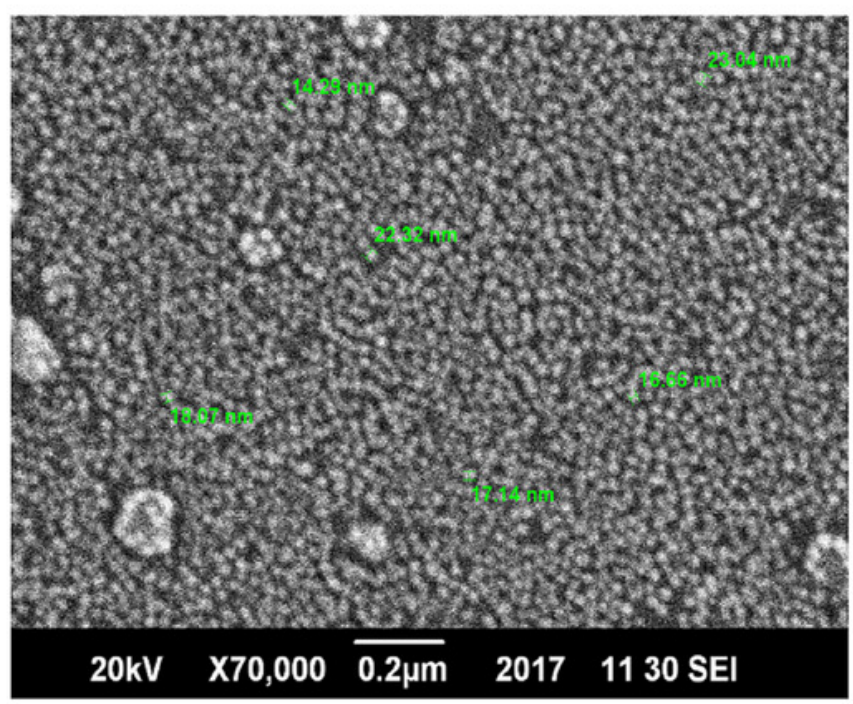

(B)

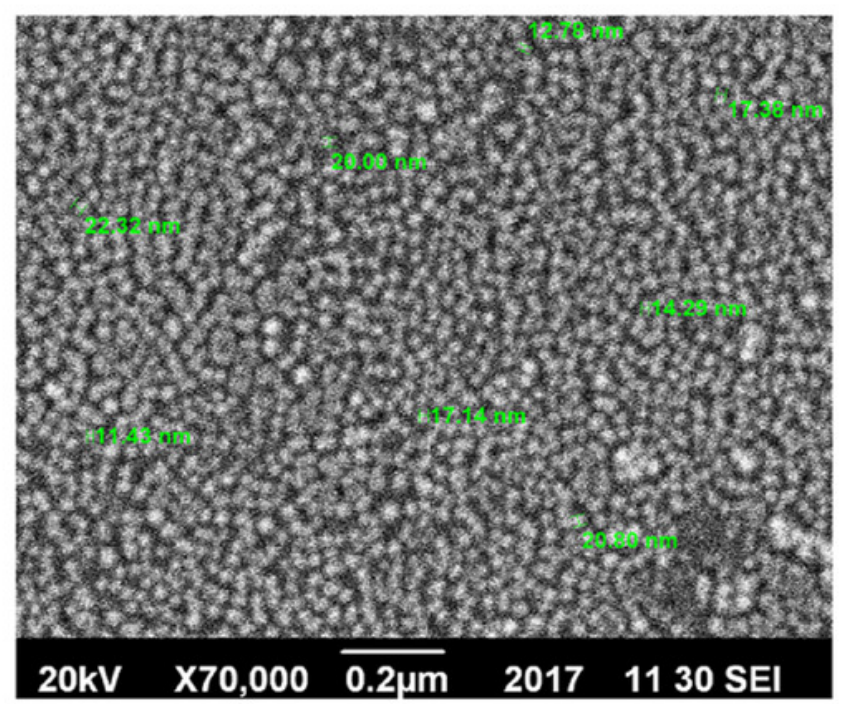




\section{Figure 4}

\section{EDX spectrum}

Energy Dispersive X-Ray image of AgNPs synthesized using Rhazya stricta

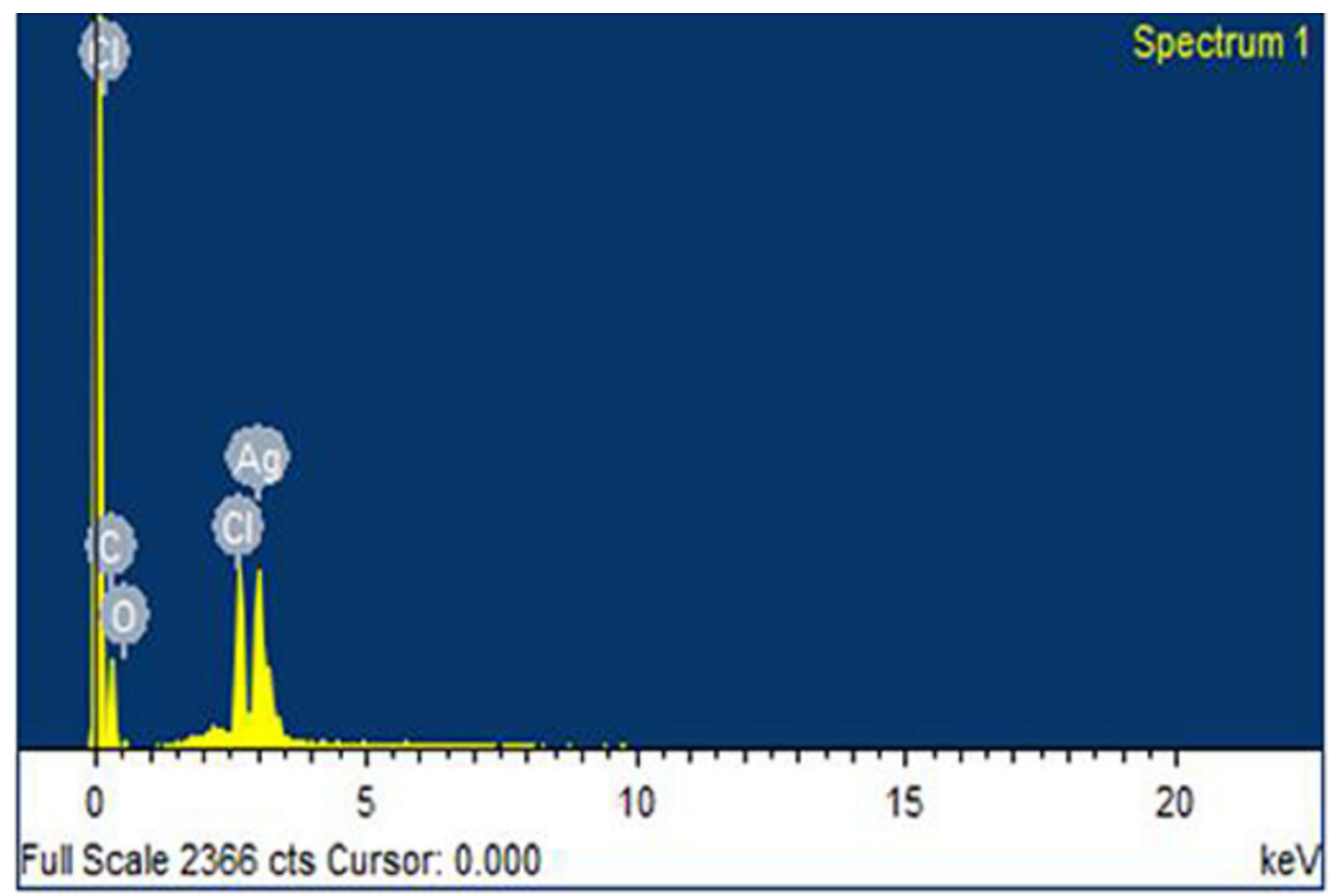


Figure 5

XRD patterens

X-Ray Diffraction (XRD) image of the AgNPs synthesized using Rhazya stricta

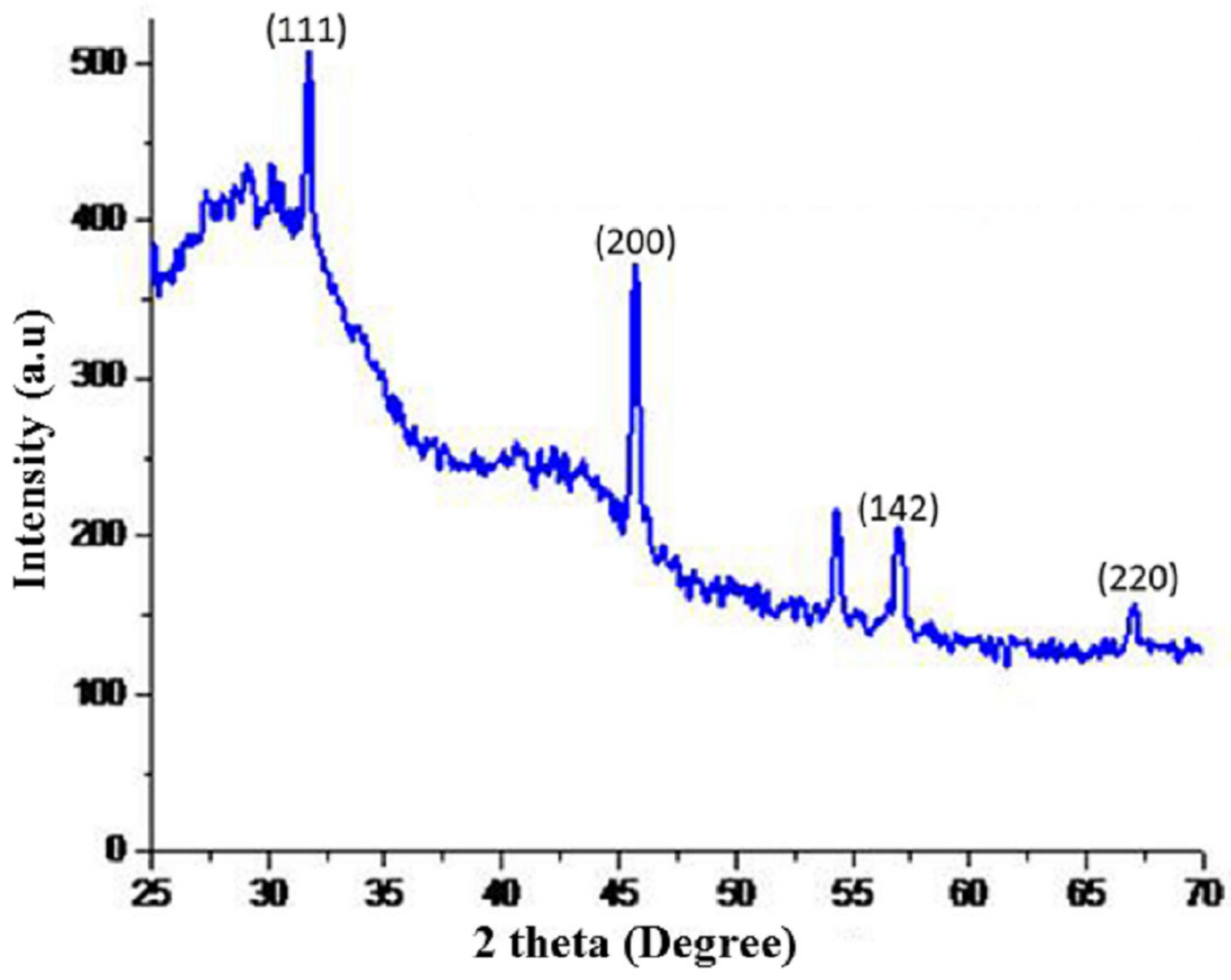




\section{Figure 6}

\section{FTIR spectrum}

(A) FTIR of Xylitol. (B) FTIR of medicinal plant R. stricta. (C) FTIR of AgNPs using Rhazya stricta. (D) FTIR of AgNPs using Rhazya stricta along with xylitol

(A)

\section{FTIR of Xylitol}

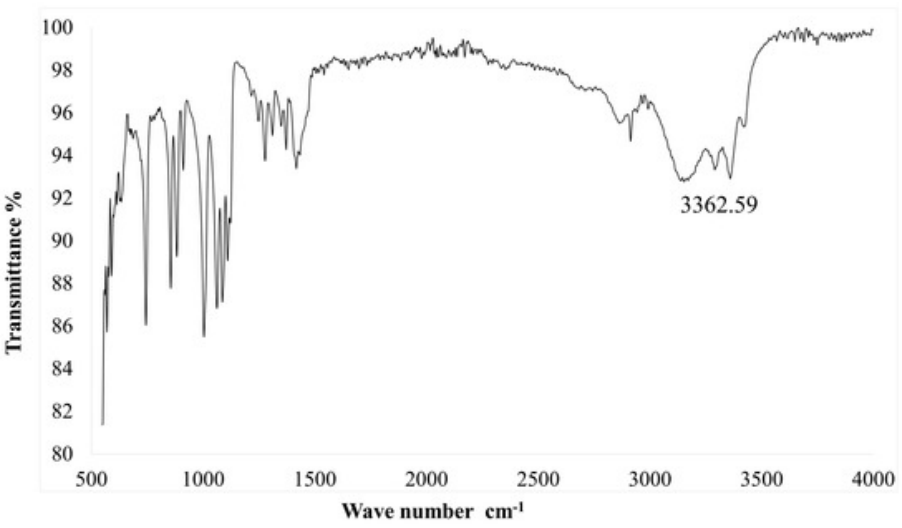

(C)

FTIR of silver nanoparticles of Rhazya stricta

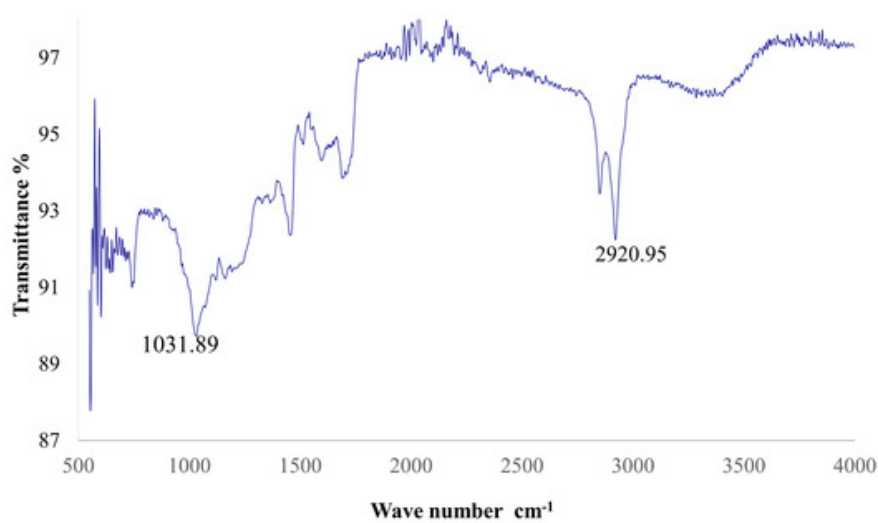

(B)

FTIR of medicinal plant Rhazya stricta

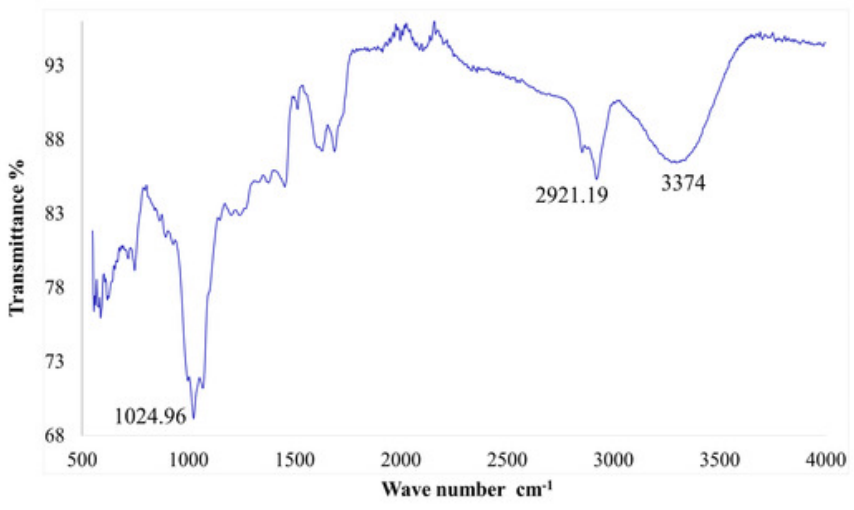

(D)

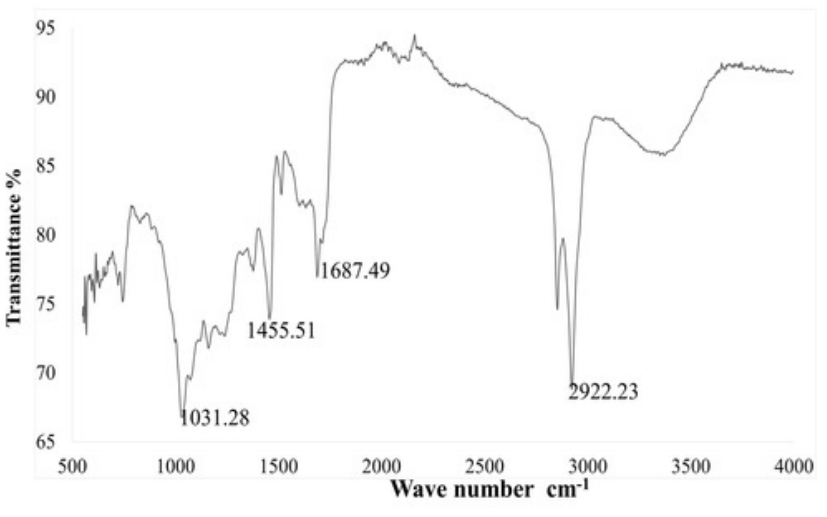




\section{Figure 7}

Concentration dependent antimicrobial activity of Ag NPs

(A) Concentration dependent effect of Bacillus subtilis. (B) Graphical presentation for concentration dependent effect of Bacillus subtilis. (C) Concentration dependent effect of Escherichia Coli. (D) Graphical presentation for concentration dependent effect of Escherichia Coli

(A)

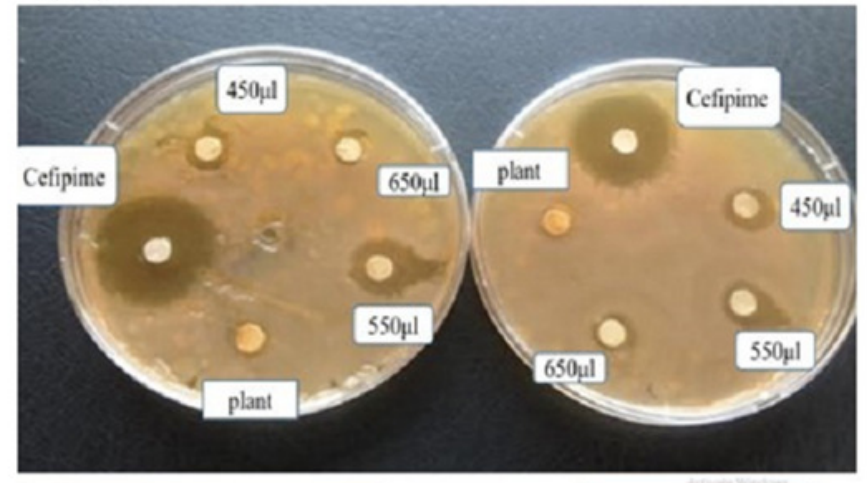

AgNps of R. stricta with xylitol

(C)

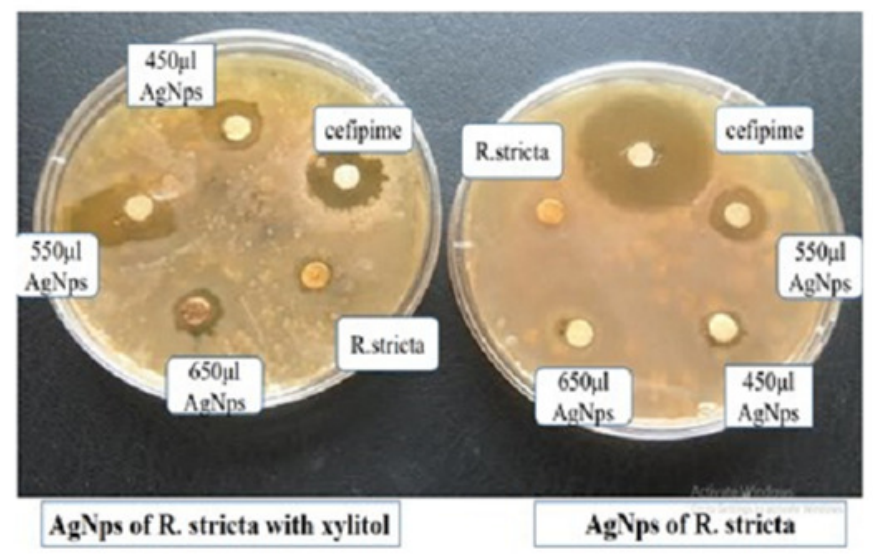

(B)

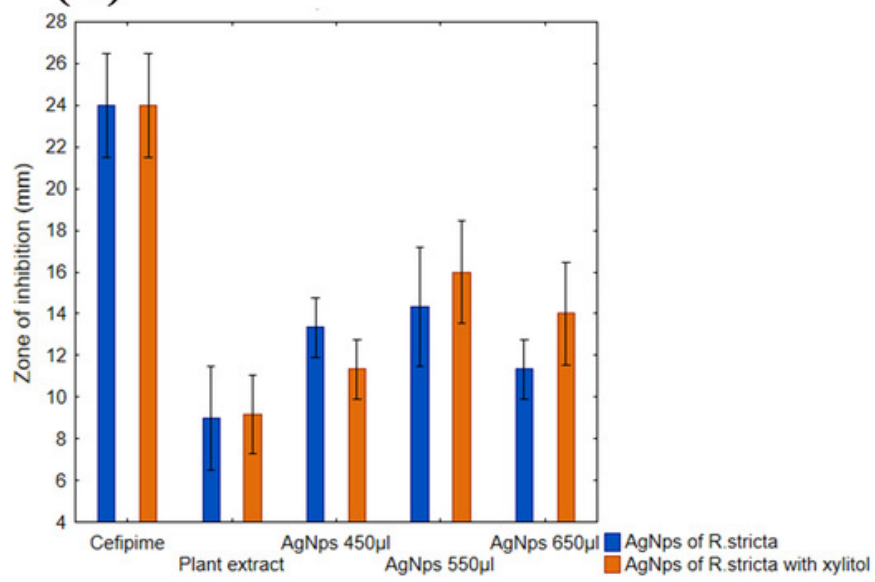

(D)

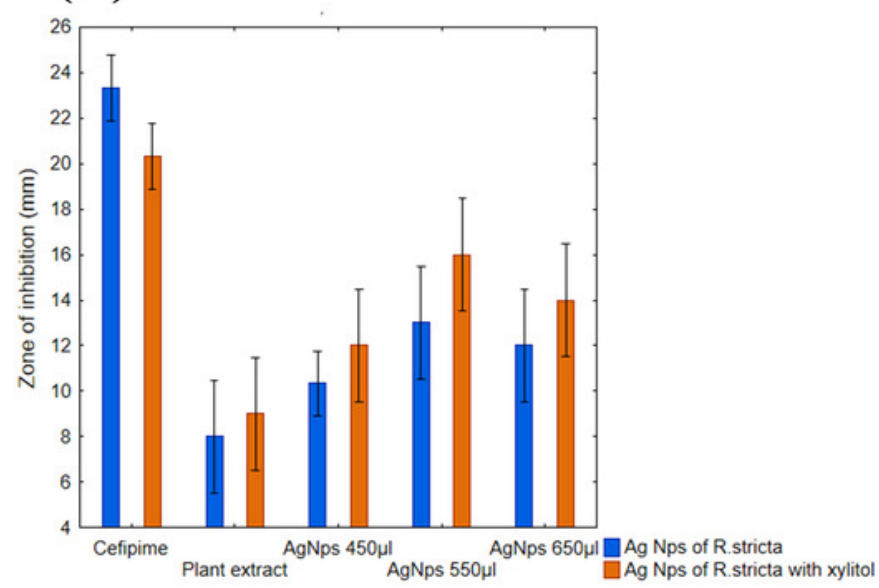


Figure 8

Time dependent antimicrobial activity of AgNPs

(A) Time dependent effect of Bacillus subtilis. (B) Graphical presentation for time dependent effect of Bacillus subtilis. (C) Time dependent effect of Escherichia Coli. (D) Graphical presentation for time dependent effect of Escherichia Coli

(A)

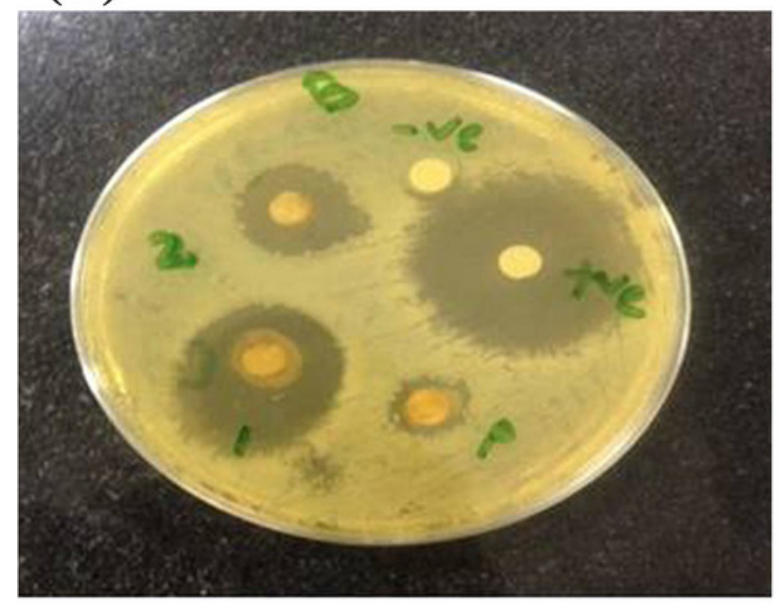

(C)

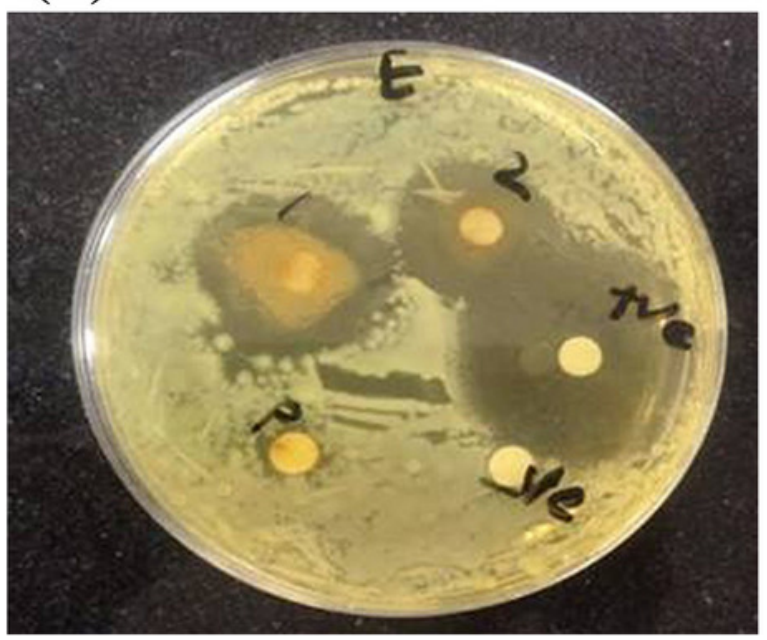

(B)

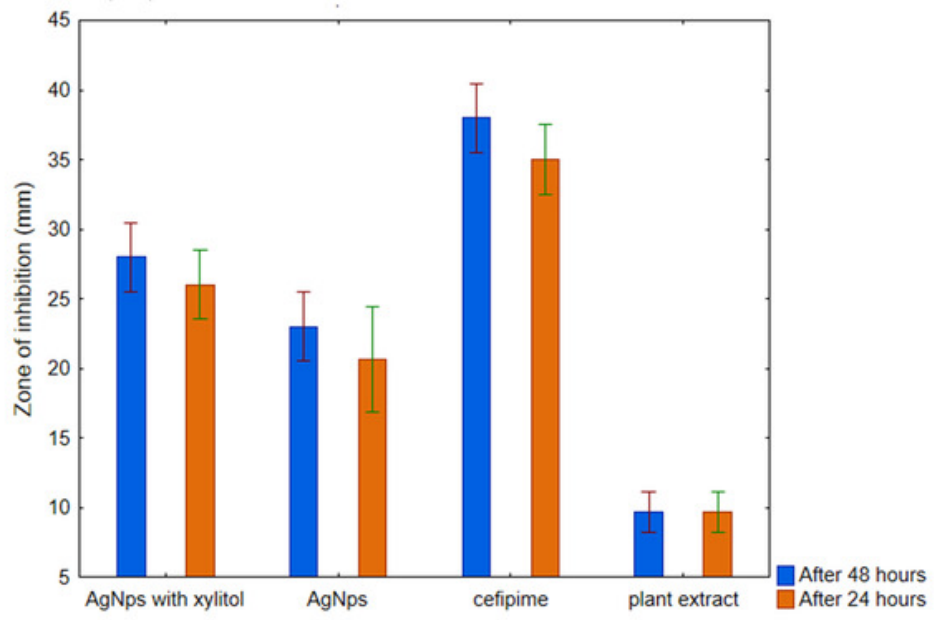

(D)

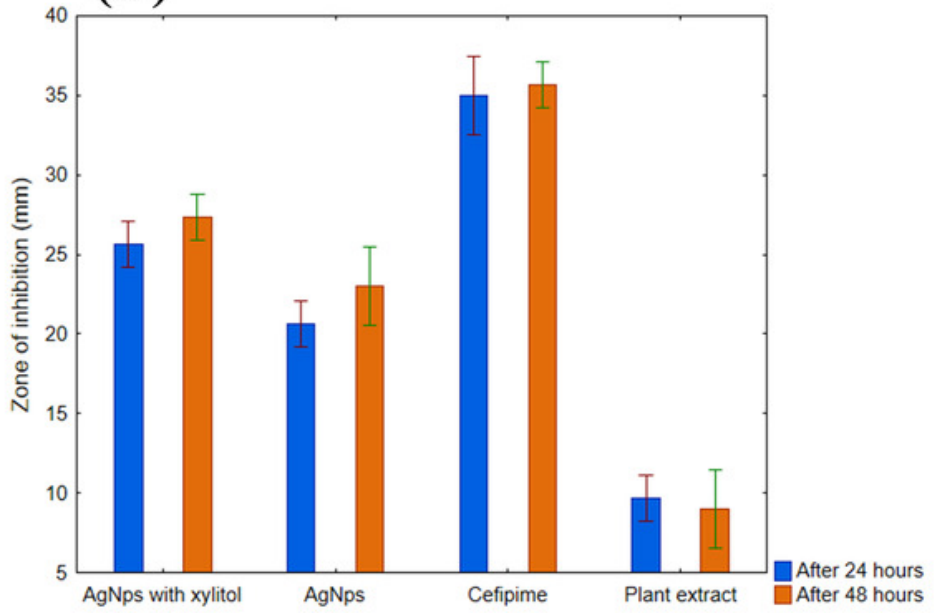




\section{Figure 9}

comparative effect of AgNPs against Escherichia Coli and Bacillus subtilis.

(A) Difference between effect of silver nanoparticles of R. stricta along with xylitol on Escherichia Coli and Bacillus subtilis. (B) Graphical presentation for comparative effect of AgNPs against Escherichia Coli and Bacillus subtilis.
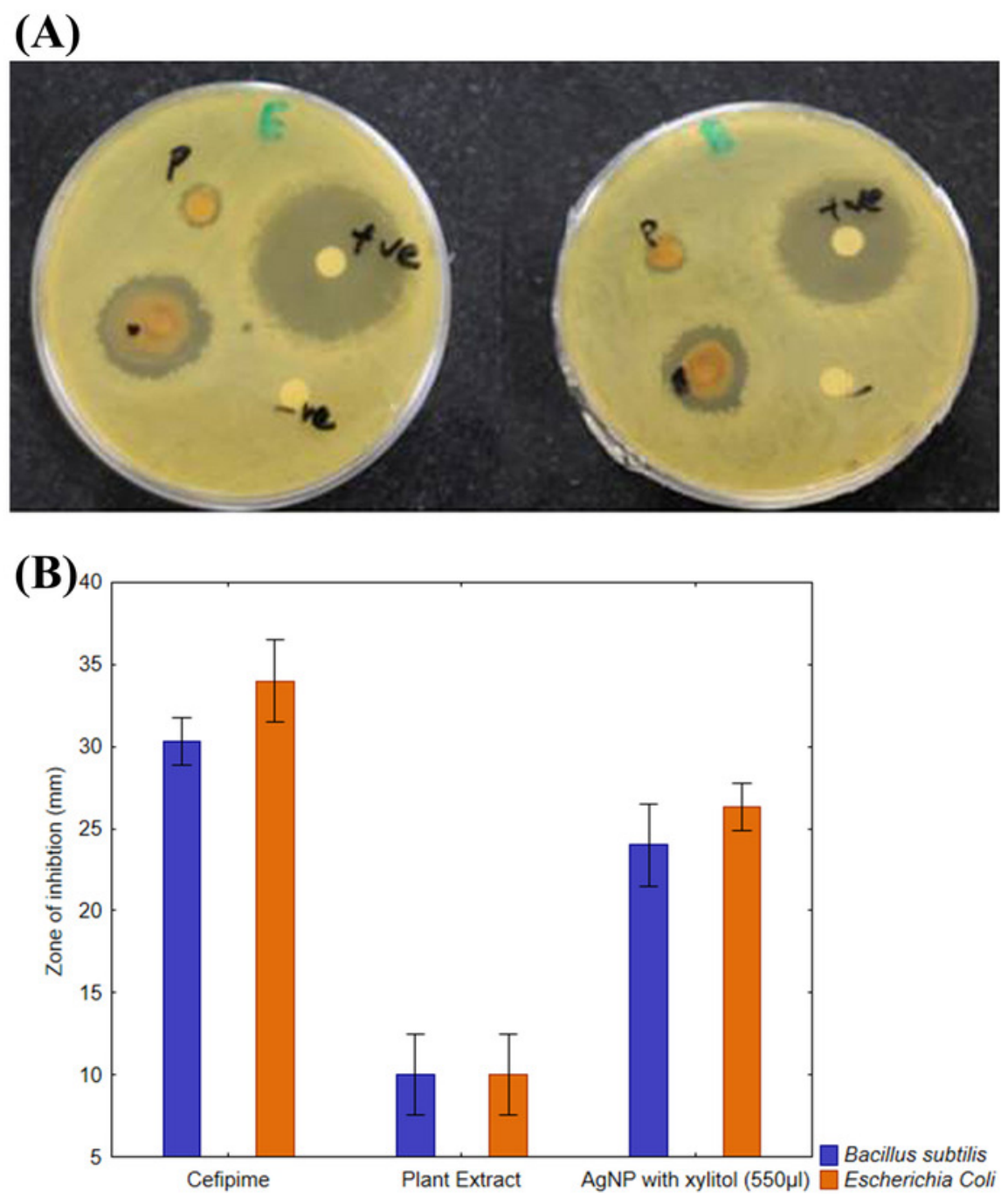